\title{
The 4 meters Bruckner test: An important tool in amblyopia screening of children with intellectual disability
}

\author{
Iulia-Andrada Nemes-Dragan, Ana-Maria Dragan, Marius Bembea
}

Faculty of Medicine and Pharmacy, University of Oradea, Romania

\begin{abstract}
The screening of amblyopia in children with special should be performed with a rapid and objective examination, such as the Bruckner test.

The hypothesis was that the 4 meter Bruckner test performed on special needs children could be at least as useful, if not superior to the 1 meter Bruckner test.

The purpose of this study was to determine the sensitivity and specificity of the Bruckner reflex at 1 meter compared to 4 meters for the detection of ametropia and strabismus in intellectual disabled children.

Material and method. The study was conducted on thirty-four patients with intellectual disabilities. Four medical students performed the 1 meter Bruckner test and then the 4 meter Bruckner test. After the test, all the patients underwent a full ophthalmological assessment, performed by the expert. The Fischer exact test and Chi square test were used to compare the results.

Results. The 1 meter Bruckner test sensitivity was between 0 and $50 \%$ and the 4 meter Bruckner test was $55.6 \%$ $72 \%(p<0.05)$. The 1 meter Bruckner test specificity was $85.7-100 \%$, while the 4 meter Bruckner test was $81.1-$ $93.8 \%(p<0.05)$.

Conclusions. Extending the distance of assessment between the examiner and the patient from 1 meter to 4 meters improves the ametropias detection accuracy.
\end{abstract}

Keywords: amblyopia, special needs children, test

\section{INTRODUCTION}

The screening of ametropia or other conditions likely to produce amblyopia, such as strabismus or cataract is an important task to be realized during the examination of a child.

For patients with intellectual disabilities who are not able to speak or to provide recognition acuity there is a need for easy and rapid tests [1].

Patients with special needs can be challenging to examine and require appropriate testing procedures, short examination times and special environment. The early detection and correction of ocular disorders will help to improve their development and growth.

The Bruckner (or red reflex) test is an indispensable objective method of detection and diagnosis of significant refractive errors (myopia, hyperopia, myopic astigmatism or hyperopic astigmatism), strabismus and amblyopia. It is a useful instrument for patients with special needs because it requires minimal patient cooperation [2].
The traditional distance that the examiner needs for assessment is 1 meter from the patient or an arm's length. This test is based on illuminating both eyes simultaneously with the ophthalmoscope and comparing the colour and brightness for symmetry. Physiologically, the red reflexes have to be symmetric in both eyes [3].

The chromatic characteristics and brightness of the red reflex depend on the light source intensity, the quality of all the transparent media, the amount of pigmentation of the fundus, and the refractive state of the eye. Increasing the distance causes weakening of the red reflex in case of ametropia, in contrast with the classic test where the reflex is brighter. Light being reflected on a divergent optical path by a hyperopic or myopic eye is the reason why distance plays an important role in the 4 meter Bruckner test. The rays of light that hit the examiner's pupil become gradually dimmer and the red reflex is reduced [4].

The higher the degree of anisometropia is, the darker the red reflex of the ametropic eye is. The 4 
meters Bruckner test can be also used to asses an overcorrection or undercorrection of the patient's glasses.

\section{WORKING HYPOTHESIS}

The 4 meters Bruckner test could be just as useful or even superior to the 1-meter test, for intellectual disabled children.

The purpose of this study was to determine the sensitivity and specificity of the Bruckner reflex at 1 meter compared to 4 meters for the detection of ametropia and strabismus in intellectual disabled children. Four Fourth year medical students played the roles of the blind observers, masked to clinical information, in order to prove the utility of the test perform by paediatricians and general practitioners.

\section{MATERIAL AND METHOD}

A prospective study was performed on thirty-four patients with intellectual disabilities, registered at the Medical Genetic Department of "Dr. Gavril Curteanu" City Hospital from Oradea. Its duration was from March 2018 to March 2019. The study was approved by the Ethical Council of the Hospital. Informed parental consent was required for each assessed patient. The selected patients were between 1 and 8 years old. The study's inclusion criteria were: patients with genetic syndromes associated with an intellectual disability (IQ test result below 70). It was proven [5] that some infants between 2 and 8 months old have asymmetric dimming of fundus reflexes. Therefore, 8-month-old infants and younger were excluded.

Before starting the study, all five students were trained in a 2-hour lab about how to perform and recognize negative or positive Bruckner reflexes using progressive minus and plus spherical or cylinder lenses to simulate ametropia [6]. During the study, the patients were first examined by the expert (pediatric ophthalmologist) and then by the 4 students. A person who wrote down the time necessary for each examiner was present at all times.

The test was performed in a dimly lit room with a direct ophthalmoscope (Beta 200, Heine, Germany). The instrument was presented to the students, who received instructions on how to hold it properly and how to look through the peephole. The patient's pupils were not dilated. Depending on age, the child would be seated either on their parent's lap or by him or herself, at a distance of about one meter from the examiner. Afterwards, the distance would be increased to 4 meters. Both patient's pupils were illuminated si- multaneously after the observers gained their attention. The student had to decide if there is asymmetry between the red reflex (positive test) or not (negative test). In cases where the compliance was very low, the children's attention was directed to cartoons playing on a smartphone or brightly lit and noisy toys, taking care that the objects' light did not interfere with the ophthalmoscope beam (Fig. 1).

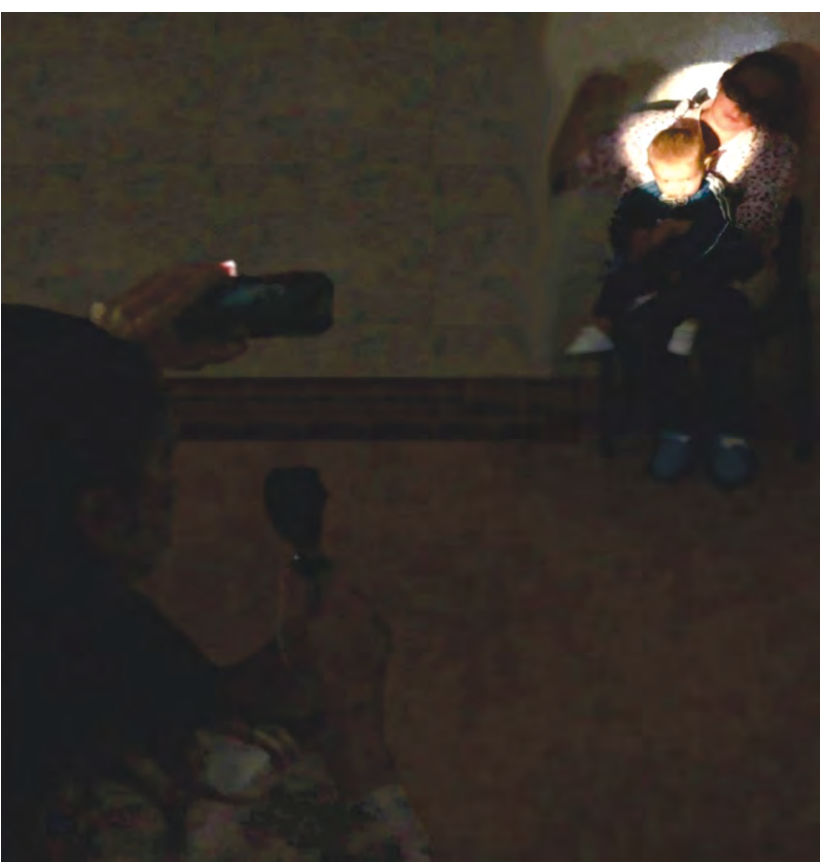

FIGURE 1. 4 meters Bruckner test performed by a student

After the test, all the patients underwent a full ophthalmological assessment, including fundus examination and cover test followed by either non-cycloplegic and cycloplegic autorefractometry (Tomey RC-800 Auto Ref/K), or retinoscopy, depending on the compliance. Cycloplegia was performed using three $10 \%$ tropicamide drops instilled 3 times, 10 minutes apart. The refraction measured after cycloplegia was considered gold standard. Spherical equivalents were used to express the errors in refraction, in order to facilitate analysis. The Fischer exact test and Chi square test were used to check if there was a link or dependency relationship between the expert and students.

\section{RESULTS}

We examined a total of 34 patients, 17 male and 17 female. All the patients had a genetic disease and most of them had an intellectual disability or were noncompliant considering their age. Most patients (28 of them) had Down syndrome, 4 had neurofibromatosis type 1, 1 was suffering from craniosynostosis and 1 from Crouzon syndrome. The mean age of the patients was 4.26 years (range 1-8 years). 
Cover test results were negative for 24 of the patients and positive for the other 10 patients who also presented with big angle manifest tropia. A total number of 21 de patients have anisometropia with a difference of more than 0.50 diopters on cycloplegic refraction (in spherical equivalent SE). At 1 meter, all students were able to correctly identify most (between $85.7 \%$ and $100 \%$ ) of the patients without a disease, but failed at identifying those with anisometropia or a deviation (correct identification ranged between $0 \%$ to $50 \%$ ) (Table 1 ).

The test sensitivity to detect a deviation or a unilateral refractive error at a test distance of $4 \mathrm{~m}$, in the hand of either student, was better when compared with the $1 \mathrm{~m}$ test. Correct identification ranged between $55.6 \%$ to $72.2 \%$ (Table 2 ).

TABLE 1. The sensitivity and specificity 1 meter Bruckner test

\begin{tabular}{|c|c|c|c|c|c|c|c|}
\hline \multicolumn{4}{|c|}{ Bruckner test $1 \mathrm{~m}$} & \multirow{2}{*}{ Total } & Sensitivity $(95 \%$ & $\begin{array}{c}\text { Positive predictive } \\
\text { value }(95 \% \text { confidence }\end{array}$ & \multirow[b]{2}{*}{$\begin{array}{l}\text { Cohen's k } \\
\text { (p-value) }\end{array}$} \\
\hline & & $\begin{array}{l}\text { with ocular } \\
\text { disease }\end{array}$ & $\begin{array}{l}\text { without } \\
\text { ocular } \\
\text { disease }\end{array}$ & & $\begin{array}{c}\text { Specificity (95\% } \\
\text { confidence interval) }\end{array}$ & $\begin{array}{c}\text { Negative predictive } \\
\text { value ( } 95 \% \text { confidence } \\
\text { interval) }\end{array}$ & \\
\hline \multirow{2}{*}{ Student1 - 1 m } & Positive & 1 & 4 & 5 & $\begin{array}{c}\mathrm{Se}=16.7 \% \\
(0.9 \%-53.9 \%)\end{array}$ & $\begin{array}{c}P P V=20 \% \\
(11 \%-64.7 \%)\end{array}$ & \multirow{2}{*}{$\begin{array}{l}K=0.004 \\
(p=0.881)\end{array}$} \\
\hline & Negative & 5 & 24 & 29 & $\begin{array}{c}\mathrm{Sp}=85.7 \% \\
(82.3 \%-93.7 \%) \\
\end{array}$ & $\begin{array}{c}N P V=82.8 \% \\
(79.5 \%-90.5 \%) \\
\end{array}$ & \\
\hline \multirow{2}{*}{ Student2 - 1 m } & Positive & 0 & 1 & 1 & $\begin{array}{c}\mathrm{Se}=0 \% \\
(0 \%-15.7 \%)\end{array}$ & $\begin{array}{c}P P V=0 \% \\
(0 \%-94.5 \%)\end{array}$ & \multirow{2}{*}{$\begin{array}{l}K=-0.005 \\
(p=0.638)\end{array}$} \\
\hline & Negative & 6 & 27 & 33 & $\begin{array}{c}S p=96.4 \% \\
(96.4 \%-99.8 \%)\end{array}$ & $\begin{array}{c}N P V=81.8 \% \\
(81.8 \%-84.7 \%)\end{array}$ & \\
\hline \multirow{2}{*}{ Student3 - 1 m } & Positive & 3 & 0 & 3 & $\begin{array}{c}\mathrm{Se}=50 \% \\
(16.8 \%-50 \%)\end{array}$ & $\begin{array}{c}P P V=100 \% \\
(33.7 \%-100 \%)\end{array}$ & \multirow{2}{*}{$\begin{array}{c}K=0.074 \\
\left(p<0.001^{*}\right)\end{array}$} \\
\hline & Negative & 3 & 28 & 31 & $\begin{array}{c}S p=100 \% \\
(92.9 \%-100 \%)\end{array}$ & $\begin{array}{c}N P V=90.3 \% \\
(83.9 \%-90.3 \%)\end{array}$ & \\
\hline \multirow{2}{*}{ Student 4 - $1 \mathrm{~m}$} & Positive & 1 & 0 & 1 & $\begin{array}{c}\mathrm{Se}=16.7 \% \\
(0.9 \%-16.7 \%)\end{array}$ & $\begin{array}{c}P P V=100 \% \\
(5.5 \%-100 \%)\end{array}$ & \multirow{2}{*}{$\begin{array}{c}K=0.024 \\
\left(p=0.028^{*}\right)\end{array}$} \\
\hline & Negative & 5 & 28 & 33 & $\begin{array}{c}S p=100 \% \\
(96.6 \%-100 \%)\end{array}$ & $\begin{array}{c}N P V=84.8 \% \\
(82 \%-84.8 \%)\end{array}$ & \\
\hline \multicolumn{2}{|l|}{ Total } & 6 & 28 & 34 & & \multicolumn{2}{|c|}{$* \mathrm{p}$-value is significant, $\mathrm{p}<0.05$} \\
\hline
\end{tabular}

TABLE 2. The sensitivity and specificity of the 4 meter Bruckner test

\begin{tabular}{|c|c|c|c|c|c|c|c|}
\hline \multicolumn{4}{|c|}{ Bruckner test $4 \mathrm{~m}$} & \multirow{2}{*}{ Total } & $\begin{array}{l}\text { Sensitivity (95\% } \\
\text { Confidence interval) }\end{array}$ & $\begin{array}{c}\text { Positive predictive } \\
\text { value ( } 95 \%\end{array}$ & \multirow[b]{2}{*}{$\begin{array}{l}\text { Cohen's k } \\
\text { (p-value) }\end{array}$} \\
\hline & & $\begin{array}{c}\text { With } \\
\text { ocular } \\
\text { disease }\end{array}$ & $\begin{array}{l}\text { without } \\
\text { ocular } \\
\text { disease }\end{array}$ & & $\begin{array}{c}\text { Specificity (95\% } \\
\text { Confidence interval) }\end{array}$ & $\begin{array}{l}\text { Negative predictive } \\
\text { value ( } 95 \% \\
\text { Confidence interval) }\end{array}$ & \\
\hline \multirow{2}{*}{ Student1 - $4 \mathrm{~m}$} & Positive & 13 & 2 & 15 & $\begin{array}{c}\mathrm{Se}=72.2 \% \\
(54.2 \%-81.2 \%)\end{array}$ & $\begin{array}{c}P P V=86.7 \% \\
(65 \%-97.5 \%)\end{array}$ & \multirow{2}{*}{$\begin{array}{c}K=0.194 \\
\left(p<0.001^{*}\right)\end{array}$} \\
\hline & Negative & 5 & 14 & 19 & $\begin{array}{c}S p=87.5 \% \\
(67.2 \%-97.6 \%)\end{array}$ & $\begin{array}{c}N P V=73.7 \% \\
(56.6 \%-82.2 \%)\end{array}$ & \\
\hline \multirow{2}{*}{ Student2 - $4 \mathrm{~m}$} & Positive & 11 & 1 & 12 & $\begin{array}{c}\mathrm{Se}=61.1 \% \\
(43.7 \%-66.4 \%)\end{array}$ & $\begin{array}{c}P P V=91.7 \% \\
(65.5 \%-99.6 \%)\end{array}$ & \multirow{2}{*}{$\begin{aligned} k & =0.168 \\
(p & \left.=0.001^{*}\right)\end{aligned}$} \\
\hline & Negative & 7 & 15 & 22 & $\begin{array}{c}\mathrm{Sp}=93.8 \% \\
(74.1 \%-99.7 \%) \\
\end{array}$ & $\begin{array}{c}N P V=68.2 \% \\
(53.9 \%-72.5 \%)\end{array}$ & \\
\hline \multirow{2}{*}{ Student3 - $4 \mathrm{~m}$} & Positive & 10 & 3 & 13 & $\begin{array}{c}\mathrm{Se}=55.6 \% \\
(37.4 \%-67.3 \%)\end{array}$ & $\begin{array}{c}P P V=76.9 \% \\
(51.7 \%-93.3 \%)\end{array}$ & \multirow{2}{*}{$\begin{array}{c}K=0.115 \\
\left(p=0.028^{*}\right)\end{array}$} \\
\hline & Negative & 8 & 13 & 21 & $\begin{array}{c}S p=81.3 \% \\
(60.8 \%-94.5 \%)\end{array}$ & $\begin{array}{c}\text { NPV }=61.9 \% \\
(46.3 \%-72 \%)\end{array}$ & \\
\hline \multirow{2}{*}{ Student4 - $4 \mathrm{~m}$} & Positive & 12 & 1 & 13 & $\begin{array}{c}\mathrm{Se}=66.7 \% \\
(49.2 \%-71.9 \%) \\
\end{array}$ & $\begin{array}{c}P P V=92.3 \% \\
(68.1 \%-99.6 \%) \\
\end{array}$ & \multirow{2}{*}{$\begin{array}{c}k=0.189 \\
\left(p<0.001^{*}\right)\end{array}$} \\
\hline & Negative & 6 & 15 & 21 & $\begin{array}{c}\mathrm{Sp}=93.8 \% \\
(74.1 \%-99.7 \%) \\
\end{array}$ & $\begin{array}{c}\text { NPV }=71.4 \% \\
(56.4 \%-75.9 \%) \\
\end{array}$ & \\
\hline \multicolumn{2}{|l|}{ Total } & 18 & 16 & 34 & & \multicolumn{2}{|c|}{${ }^{*} p$-value is significant, $p<0.05$} \\
\hline
\end{tabular}


The expert had a significantly shorter response time (diagnosis) at 1 meter and also at 4 meters than students 1, 2, 3 and 4 (Mann Whitney $U$ test: $p<$ 0.0125 with Bonferroni correction).

There was no significant difference between the students regarding the speed of applying the Bruckner method at $1 \mathrm{~m}$ (Mann Whitney U test: $\mathrm{p}<0.0125$ with Bonferroni correction) in contrast with the $4 \mathrm{~m}$ test where there was a significant difference between the students regarding the speed (Kruskal Wallis test: $\mathrm{p}=$ $0.434>0.05)$.

Focusing only on those patients who had a positive cover test, we can observe that the students performing evaluations at $1 \mathrm{~m}$ had difficulty in correctly identifying those who were ill compared to the expert's assessment, correct illness identification ranging from $0 \%(0 / 6)$ to $50 \%(3 / 6)$. At $4 \mathrm{~m}$, we observed an increase in the rates of correct illness identification, which ranged from $12.5 \%(1 / 8)$ to $87.5 \%(7 / 8)$.

\section{DISCUSSIONS}

The results of our study show that the classic Bruckner test realized at 1 meter has excellent specificity (between $87.5 \%$ and $100 \%$ ) and good negative predictive values (between $81.8 \%-91.3 \%$ ) for detecting high anisometropia or strabismus on intellectually disabled children even in the hands of a non-ophthalmologist [6-9].

However, when the distance of examination is increased to 4 meters, the sensitivity improves dramatically (from $16.7 \%$ to $72.2 \%$ ) [6,8]. Strabismus was also detected more accurately at a test distance of $4 \mathrm{~m}$ in comparison with the $1 \mathrm{~m}$ test.

The La Mattina K et al. study was designed to determine the validity of the red reflex test for anisometropia, proving that it can be a quick and inexpensive tool for pediatricians if they have appropriate training, and an accurate method for pediatric ophthalmologists [10].

Kothari et al. compared the 1 meter Bruckner test with conventional vision screening in school children in India, where the test had an excellent sensitivity $(88 \%)$ and negative predictive values (99\%) [11].

The reason this study had better results was probably because it was performed on high school children without intellectual disability [12].

Jalis $\mathrm{M}$ et al. proved the usefulness and timeliness of the 1 meter Bruckner test to detect significant spherical and aspheric refractive errors in infants, mentioning that increasing the distance brings an improvement in accuracy [13].

The overall sensitivity of the $1 \mathrm{~m}$ test was similar with ours in a study conducted in the UK by Muen W et al. $(14.3 \%)$. They concluded that even if in the UK the red reflex test is popular and performed by most of the GP's, there is a need for more tests with higher sensitivity [14].

Amitava et al. tried to simplify and reduce the Bruckner test costs by using retinoscopy. They obtained similar results to the classic test, with above $90 \%$ accuracy [15].

A different way to perform a quick and efficient screening was developed by Bani $\mathrm{S}$ et al. through the use of a digital camera for detecting anisometropia and strabismus, analyzing after that the Bruckner reflex, offering a useful alternative for amblyopia screening in developing countries, with an accuracy similar to that of Amitava's study [15,16].

Studies conducted by Graf M and Jain et al. revealed an excellent clinical agreement between ophthalmologists and non-ophthalmologists, using an enhanced Bruckner test $[6,17]$.

\section{CONCLUSIONS}

The Bruckner test can be an excellent and fast adjuvant test for pediatricians, orthoptists and general doctors given appropriate training. The accuracy of the test for detecting ametropia or strabismus improves if you increase the distance of examination. Thus it can be a reliable tool for patients with intellectual disabilities for whom a shorter distance can reduce compliance.

\section{REFERENCES}

1. Taub M. Comprehensive Examination Procedures. In: Taun M, Bartuccio M, Maino D Visual Diagnosis and Care of the Patient with Special Needs. Wolters Kluwer Health, 2012,155-184.

2. Stephen E, Dickson J, Kindley A. Surveillance of vision and ocular disorders in children with Down syndrome. Dev Med Child Neurol. $2007 \mathrm{Jul} ; 4$ 49(7):513-5.

3. Lambert S, Lyous C.Taylor and Hoyt's Pediatric Ophthalmology and Strabismus. Edinburgh: Elsevier, 2017.

4. Graf M. The Bruckner test revised. In: Lorenz B, Brodsky M. Pediatric Ophtalmology, Neuro-Ophtalmology, Genetics. Springer. Heidelberg, 2010, 113-124.

5. Archer S. Developmental aspects of the Bruckner test. Ophthalmology.1988 August: 1098-1101.

6. Graf M, Jung A. The Brückner test: Extended distance improves sensitivity for ametropia. Graefes Arch Clin Exp Ophthalmol. 2008 Jan;246(1):135-41.

7. Roe L, Guyton D. The light that leaks: Brückner and the red reflex. Surv Ophthalmol. 1984 May-Jun;28(6):665-70.

8. Paysse E, Williams $G$, Coats $D$ et al. Detection of red reflex asymmetry by pediatric residents using the Brückner reflex versus the MTI photoscreener. Pediatrics. 2001 Oct;108(4):E74. 
9. Gole G, Douglas L. Validity of the Bruckner reflex in the detection of amblyopia. Aust N Z J Ophthalmol. 1995 Nov;23(4):281-5.

10. LaMattina K, Vagge A, Nelson L. Can the Red Reflex Test Detect Unequal Refractive Error? J Pediatr. 2019 Aug 1.

11. Kothari M, Kosumbkar S. Ultra-rapid school vision screening in developing nations using the Brückner test. Am Orthopt J. 2010; 60:82-6.

12. Kothari M. Can the Bruckner test be used as a rapid screening test to detect significant refractive errors in children? Indian J Ophthalmol. 2007 May-Jun;55(3):213-5.

13. Jalis M, Ashfaq M, Imdad A. Use of Bruckner Test for the Detection of Significant Refractive Errors in Children. Journal of Rawalpindi Medical College (JRMC); 2015;19(3):200-203.
14. Muen W, Hindocha M, Reddy M. The role of education in the promotion of red reflex assessments. JRSM Short Rep. 2010 Oct; 1(5):46.

15. Amitava A, Kewlani D, Khan Z, Razzak A. Assessment of a modification of Brückner's test as a screening modality for anisometropia and strabismus. Oman J Ophthalmol. 2010 Sep; 3(3):131-5.

16. Bani S, Amitava A Sharma R, Danish A. Beyond photography: Evaluation of the consumer digital camera to identify strabismus and anisometropia by analyzing the Bruckner's reflex. Indian J Ophthalmol. 2013;61:608-11.

17. Jain P, Kothari M, Gode V. The opportunistic screening of refractive errors in school-going children by pediatrician using enhanced Brückner test. Indian J Ophthalmol. 2016 Oct; 64(10): 733-736.

Conflict of interest: none declared Financial support: none declared 